\title{
Expresiones de resistencia Afrocaribe: La mirada decolonial en la obra poética de Jorge Artel
}

\author{
Expressions of Afrocaribe resistance: \\ The decolonial look at Jorge Artel's poetic work
}

\author{
Matilde Eljach \\ Socióloga, Doctora en Antropología. Docente Investigadora de la Universidad Simón Bolívar de Barranquilla, \\ Grupo de investigación Historia Sociedad y Cultura Afrocaribe, línea de investigación Resistencias \\ y construcción de territorio e identidad. \\ Email: meljach1@hotmail.com
}

Kebby Romero-Sierra

Investigador del CIISO de la Universidad Simón Bolívar (Barranquilla-Colombia), integrante del grupo de Investigación y Estudios Interdisciplinarios del Caribe, Doctorando en Ciencias Sociales de la Universidad de Salamaca (España), Historiador y Magíster de Historia de la Pontificia Universidad Javeriana Email: kebbyrs25@gmail.com

Doi: https://doi.org/10.22267/rceilat.204647.89

$$
\begin{array}{r}
\text { “...Voces claras para el alma } \\
\text { Turbia de sed y ansiedad....” } \\
\text { (Jorge Artel) }
\end{array}
$$

\section{Resumen}

Hablar de resistencia afrocaribe, conduce a recrear la memoria y caminos trasegados por hombres y mujeres como Candelario Obeso, Luis Antonio Robles, Juan, Delia y Manuel Zapata Olivella, Aquiles Escalante y Jorge Artel, entre otros; quienes nos legaron su palabra y su compromiso en la lucha por la identidad, la recuperación y dignificación de la memoria del pueblo afrodescendiente, a través de su producción intelectual, como investigadores, narradores, folcloristas y poetas. Este ensayo hace referencia en clave decolonial al poeta Jorge Artel. Poeta de su raza y de su gente, de sus tambores y de protestas llenas de vida, de negritud, de emoción sin límites, de angustia ancestral y llamado de la sangre. Jorge Artel intuyó, supo, comprendió, que la modernidad es un pozo negro que con la retórica del progreso, oculta sus consecuencias, así como también oculta la energía irreductible de los marginados y excluidos de la tierra.

Palabras clave: Resistencia; Afrocolombianidad; Poética; Identidad. 


\begin{abstract}
Speaking of Afro-Caribbean resistance leads to recreating the memory and paths traveled by men and women such as Candelario Obeso, Luis Antonio Robles, Juan, Delia and Manuel Zapata Olivella, Aquiles Escalante and Jorge Artel, among others; who bequeathed to us their word and their commitment in the fight for identity, recovery and dignification of the memory of the Afro-descendant people, through their intellectual production, as researchers, narrators, folklorists and poets. This essay makes a decolonial reference to the poet Jorge Artel. Poet of his race and of his people, of his drums and of protests full of life, of blackness, of boundless emotion, of ancient anguish and call of blood. Jorge Artel intuited, knew, understood, that modernity is a cesspool that with the rhetoric of progress, hides its consequences, as well as hides the irreducible energy of the marginalized and excluded from the earth.
\end{abstract}

Key words: Resistance; Afro-Colombian; Poetic; Identity.

\section{Introducción}

La palabra es una herramienta emancipadora cuando nace en cerebros prolijos, este es el caso de Jorge Artel. Su contexto histórico posibilita una lectura de su propuesta poética desde la clave decolonial. Este es el sentido de las siguientes líneas, más que realizar un análisis desde las herramientas metodológicas de la poesía, ubicaremos al poeta en su postura política y cómo esta se encuentra inmersa en su producción. Por ello, hemos dividido el texto en tres momentos, la vida del poeta desde su postura política, la lectura de su obra desde el enfoque decolonial y por último, mostraremos la relación entre este enfoque político con su poesía.

\section{La vida del poeta desde su postura política}

Aunque el término política es polisémico, éste aduce a todo aquello que involucra al ciudadano y los asuntos públicos, para otros, la política es un todo que envuelve la forma en cómo vemos y entendemos el mundo desde nuestro aparato ideológico. Lo cierto es, que como producto de nuestro contexto todos los seres somos políticos por naturaleza. Aunque Artel no fue un perseguido político por la falta de una dictadura directa al estilo español como el caso de Federico García Lorca o quizás porque en sus épocas de juventud y adultez el período de la violencia bipartidista (en Colombia) se dio con mayor fuerza en el centro del país que sobre sus costas en el Caribe colombiano, la turbulenta realidad política de la Colombia entre los años de 1940 y 1970 no lo eximió ni alejó de su activismo político en favor de las causas sociales.

Sin embargo, cuando hablamos de la vida y obra de personajes célebres siempre partimos de lugares comunes que además nos permiten ubicar 
al personaje, en este caso Agapito de Arco Coneo (cuyo seudónimo fue Jorge Artel) se inclinó por el periodismo y la poesía, género en el cual se destacó como máximo representante de la poesía "negra" en Colombia, su obra encierra las claves de un llamado a la libertad y la identidad como caribeños. Nació en el barrio de Getsemaní en la ciudad de Cartagena: el 27 de Abril de 1909 y murió en Malambo (Atlántico) el 20 de Agosto de 1994. Perteneció al grupo de intelectuales colombianos que reivindicaron la causa Afro en el siglo XX.

Bachiller en Filosofía y Letras del Instituto Politécnico de Martínez Olier. Abogado de la Universidad de Cartagena (1945) con la tesis "Defensa preventiva del Estado o el Derecho Penal frente a los problemas de la cultura popular en Colombia”. Fue Jefe de Instrucción Pública en el Departamento de Bolívar, Inspector de Policía del Corregimiento de Santa Elena, un populoso sector de Medellín.

Es autor de los libros "Tambores en la noche" (1940), "Modalidades artísticas de la Raza Negra", "Sinú, riberas de asombro jubiloso", "Poemas con botas y Banderas" (1972), "Coctel de Estampa y Antología poética” (1979), "Poesía Negra", "No es la muerte es el morir" (Novela) (1979), y la obra de teatro "De rigurosa etiqueta". Además escribió algunos tratados sobre el Derecho Penal en Colombia.

Aunque Jorge Artel es reconocido por su obra y su significado desde la reivindicación de la cultura afro- caribe, en su texto "Tambores en la noche y selección de poesía inédita" publicado por Jorge Nazim Artel Alcázar (hijo del poeta) en diciembre del 2004 en Barranquilla, se incluyen algunos comentarios de amigos cercanos como Nicolás Guillén o Apolinar Díaz-Callejas que nos permiten ubicar de mejor forma algunas de sus posturas políticas.

Jorge Nazim Artel muestra desde una esfera endógena la relación de su padre con el sindicalismo colombiano, su postura antifranquista y su profundo compromiso por las causas sociales. Todo un revolucionario moderno. El hito histórico de la revolución cubana, significó no solo para él sino también para la mayoría de los intelectuales la posibilidad de derrocar a las oligarquías latinoamericanas que usufructuaban del poder del Estado. Por eso Artel escribió "Esquema para un canto a Fidel Castro", en el que dijo:

Fidel Castro es la estampa viviente y victoriosa

Fidel Castro tiene ahora la bandera, Con las propias glándulas de Cuba Forjó compactas legiones Y dio a la revolución una conciencia. Su vegetal raigambre se ha prendido

Más allá de oferentes y fértiles espigas

En los íntimos pedernales de su tierra

$$
\text { (...) }
$$

Cuba: ante su estrella solitaria, Se detiene un poeta.

La muerte de Gaitán, el gobierno de transición del General Rojas Pinilla, el 
Frente Nacional, la revolución Cubana y el fracaso de la ANAPO bajo la presidencia de Misael Pastrana Borrero, fueron algunos de los hechos políticos que impactaron a la mayoría de los jóvenes de las urbes colombianas que creían posible la construcción de un nuevo país. El humanismo como forma de lucha, explica Mauricio Archila en su texto Idas y venidas, vueltas y revueltas: protestas sociales en Colombia, 1958-1990, se constituyó desde las universidades de las urbes como el máximo movimiento alternativo nunca antes visto en nuestro país movido por los hombres y mujeres de esas generaciones, lucha de la cual Artel hizo parte como miembro del Partido Comunista.

No es gratuito que la esquina de lucha de Artel haya sido una poesía transgresora de los cánones europeos, que su lugar de construcción sea su realidad de esa Cartagena oligarca y racista constituyendo una postura contra hegemónica.

Cartagena de Indias es una ciudad que soporta sus relaciones sociales con base en la herencia colonial, una ciudad que divide a la élite heredera del criollismo contrapuesta con la gran masa negra y mestiza pobre que vive en los barrios periféricos, una ciudad que excluye del territorio de blancos, a los negros, una ciudad hecha para complacer los deseos de los turistas propios y foráneos pero que margina lo negro en las labores que por "tradición” estamos llamados a hacer. La obra de Artel es sin duda una respuesta a este orden colonial impuesto por las élites locales, unas élites blanqueadas que no permiten lo negro en ciertos espacios, solo basta darse una vuelta por los clubes de la ciudad o buscar a los oficiales de la marina colombiana para entender la problemática.

En consecuencia, las características anteriormente expuestas contienen todas las herramientas para realizar un análisis de una parte de su obra con el enfoque decolonial, expresado no solo desde la resistencia sino también de su activismo político. En profundidad, su obra es una respuesta al contexto colonial, una respuesta a su realidad política.

\section{Jorge Artel una lectura en clave decolonial}

Son varios los trabajos e investigaciones de análisis literario cuyo eje central es la obra poética de Jorge Artel $^{1}$, fundamentados en la reconfiguración de la identidad de lo afro la cual entra en disputas desde las formas estéticas del discurso periférico con las formas del canon tradicional hispánico. Esta riqueza discursiva del trabajo de Artel ubica a la escritura como un

1 Trabajos como: Hortensia Naizara Rodríguez, La poética de Jorge Artel más allá del Estado-Nación, Revista Centro Americana, Università Cattólica del Sacro Cuore, Milano-Italia, 2014, pág. 39-63; Marcelo José Cabarcas Ortega, La figuración poética de la identidad: lo negro en Tambores en la noche de Jorge Artel, Revista de Estudios de literatura Colombiana, Número 32, Enero-Junio, 2013, pág. 73-86; Ayleen Julio Díaz, La construcción de lo afro en la poética de Jorge Artel, Revista Cuadernos de literatura del Caribe e Hispanoamérica, Número 9, Enero-Junio, 2009, pág. 95-106. 
espacio de confrontación cultural que posibilita la reconfiguración de ese otro obviado por el canon tradicional con base en la representación de su africanidad. En tal sentido, la escritura entendida como un producto social posibilita el análisis de las tensiones del contexto creativo, ya que permite no solo ubicar al autor y su obra sino que clarifica la comprensión dado que se parte de su lugar de enunciación.

Cartagena, una sociedad negrera y profundamente racista trató de blanquear lo negro bajo la falsa idea del mestizaje, configuró, lo mulato como el estandarte de la limpieza de la sangre en la mezcla de la península Ibérica y África desde los tiempos del proceso de invasión de los nuevos territorios que mal llamaron América. Boaventura De Sousa Santos (2009), en su texto Epistemologías del sur plantea la desconexión entre la teoría y la práctica, ya que la teoría no habla con la práctica y la práctica no habla con la teoría, la cual él denomina como una relación fantasma, la no fidelidad al canon hispánico ubica a Artel y su obra, en el medio de esta desconexión que planea Sousa, dejando solo como posibles rutas de esta actitud rebelde la resignificación de la identidad afro y su agencia política.

Por lo tanto, en la obra de Artel se pueden identificar dos posiciones políticas frente al imaginario de una subordinación periférica, la resignificación de la identidad Afro en la narrativa de una sociedad racializada como la del Caribe colombiano y una distancia estética frente al canon hispánico de los Andes. El profesor camerunés Alain Lawo-Sukan (2010) muestra la distancia hegemónica entre los Andes y las costas Atlántica y Pacífica en su texto Hacia una poética afro-colombiana: el caso del Pacífico, y cito: En el plano literario, se dio a conocer en Colombia al que es considerado como el precursor de la poesía afro-hispánica: Candelario Obeso (1849-1884). A pesar de su valor literario, la mayoría de los escritores afro-colombianos siguen siendo pasados por alto en los principales anales, bibliografías, antologías e historias de la literatura colombiana. El ejemplo de Juan Gustavo Cobo Borda indica la magnitud de tal descuido literario. Conocido por sus talentos literarios y críticos, ni siquiera menciona en su antología canónica, Historia portátil de la poesía colombiana 1880-1995, a los escritores de ascendencia africana.

El culto al positivismo cientificista expresado en un canon literario eurocéntrico concibió y concibe las expresiones afro como marginales-periféricas, no propias de la cultura de los Andes impuestas por unas élites blanqueadas, según ellos, favorecidas por el influjo del clima frio bajo la hipótesis que la poca mezcla racial de las élites andinas, permitió conservar la naturaleza de su ancestralidad europea. El pensamiento de Francisco José de Caldas aún retumba en el imaginario colectivo de algunos sectores de las élites andinas colombianas; negarlo, es negar en sí mismo nuestra realidad.

Por fortuna, existen obras como la de Jorge Artel que logran romper las fronteras hegemónicas del conoci- 
miento; con su obra demuestra una forma de diálogo entre la tradición y lo moderno, entre el discurso y la realidad. La negrura, o mejor su negritud, se posiciona como un acto de reinvindicación cultural cargado de una legitimidad política dado que lleva implícito la cosmogonía africana.

Los efectos de la colonialidad necesariamente se constituyen desde el lenguaje, es la enunciación la que da forma a la taxonomía social. Es por ello, que la colonialidad comienza y concluye con el lenguaje, dado que éste proporciona términos que construyen la realidad marcando la pauta en cómo interactuamos los seres humanos en sociedad. Reinvindicar la africanía a través de la poesía, es un ejercicio de hibridación cuyo objetivo apunta a desequilibrar los elementos hegemónicos generando nuevos espacios y nuevas formas de poder, de saber y de ser.

Michel de Certeau (1986), expone que el bricolaje es una estrategia que emplea el marginado para crear una cultura propia de los remanentes del grupo dominante. Constituye una práctica de evasión y resistencia que, cuando se refiere a una creación visual, la hegemonía cultural designa como artesanía y no arte. Este escenario del poder de la colonialidad y el uso de las artes para desbalancear los cánones impuestos han sido una estrategia fuertemente usada en el Caribe colombiano no solo por Jorge Artel sino también por otros escritores afrocaribeños de la talla de Manuel Zapata Olivella.
Esta actitud descolonizadora conlleva de fondo una postura política en respuesta a la colonialidad sobre la cual se cimentó el proyecto moderno, ubicando a Latinoamérica en el Tercer Mundo carente de desarrollo y caracterizado por la pobreza. Para el caso colombiano nuestras élites han sido garantes de este discurso modernizador y en respuesta encontramos en la poética de Artel, la reinvindicación no solo de lo afro sino también de lo local como el territorio desde el cual el poeta reconstruye su africanidad caribeña. Lo local cobra importancia en el análisis decolonial, porque aporta las herramientas para mediar con los discursos hegemónicos.

En efecto, lo local es un transgresor del orden hegemónico debido a que impone su realidad, sus lógicas, sus formas, su cosmogonía. En este sentido, dialogando con la poeta cartagenera Hortensia Naizara Rodríguez (2014), quien le pregunta cómo surgió la voz de los ancestros, Jorge Artel respondió:

“Tenía la urgente necesidad de escuchar el silencio, de indagar en sus símbolos y una noche decidí llegar hasta el puente Román de Cartagena, me encontraba en un momento emocional que no podría narrar, sentía cada vez más cerca las voces del viento y de las gentes de mis antepasados, entonces me dije que era el mensajero del viento y de mis ancestros, fue así como empecé a escribir este poema que era un sueño obsesivo", haciendo alusión a su poema "La voz de los ancestros". 
Las referencias a lo local como territorio en su obra le da vida a su ancestralidad, son las características del espacio las que usa como forma de resistencia, como reconstrucción de su alteridad afrocaribe. Este punto de partida, muestra cómo su poesía se posiciona desde la resistencia evocando la memoria de los ancestros, el valor de la noche como cómplice de la libertad y el ruido de los tambores como el sonido de las palabras desde las cuales reconstruye su oralidad.

Desconocer el valor de lo local como un espacio de resistencia se configura como un intento de invisibilizar las otras realidades que hacen parte del acervo cultural de la nación, desconocer la realidad ya sea por ignorancia o por omisión como lo fue el caso de Juan Gustavo Cobo Borda es solo un ejemplo de la miopía de algunos sectores académicos tradicionales.

En la poesía de Jorge Artel se encuentran todos los elementos que configuran un discurso desde el enfoque decolonial, la resistencia al lenguaje modernizador, un carácter reinvindicatorio y una necesidad emancipadora. Su postura política habla por sí sola.

\section{“...Los vientos, mil caminos ebrios y sedientos..."}

$\mathrm{Al}$ estudiar la producción intelectual o artística de un académico, o de un poeta como Jorge Artel, usualmente el énfasis se centra en lo lingüístico, en lo musical, en lo literario; como espacio donde convergen tensiones y controversias de tipo cultural, representaciones que validan los proyectos estéticos alternativos, como lo expone Marcelo José Cabarcas Ortega (2013); o indagan por la ruptura con los estándares gramaticales imperantes en un momento histórico, con la cual el poeta ofrece el "desorden" que permite que afloren nuevos paisajes culturales, al decir de Hortensia Naizara Rodríguez (2014).

Igualmente no faltan los estudios comparativos entre el poeta Jorge Artel y otros insignes representantes de la poética afrocaribeña como Nicolás Guillén, fundador de la corriente denominada "Afrorrealismo" (Duncan, 2013), con la que se identificó Artel, así como con el Candelario Obeso de "Cantos populares de mi tierra" (2009), en los que se destacan críticamente los valores de la afrodescendencia.

Desde una mirada cultural, centrada en el folclor, se analiza la participación de la música, la danza, la sensualidad femenina, la naturaleza, la religiosidad de los pueblos africanos, como elementos sustanciales de la obra de Artel, como en el trabajo de Manuel Guillermo Ortega Hernández (2006), el cual enlaza a este con otros grandes representantes de la poética afroamericana y caribeña como Nicolás Guillén, Helcías Martán Góngora, Candelario Obeso, Manuel del Cabral, Langston Hughes, Luis Palés Matos y el Tuerto López.

En este ensayo, queremos abordar desde el enfoque decolonial, la poesía militante, resistente de Jorge Artel, 
que confronta la institucionalidad, que rompe los esquemas para construir otros posibles caminos.

Hablar de resistencia afrocaribe, nos conduce a recrear la memoria y los caminos trasegados por hombres y mujeres de la talla de Candelario Obeso, Luis Antonio Robles, Juan, Delia y Manuel Zapata Olivella, Aquiles Escalante y Jorge Artel, entre otros; quienes nos legaron su palabra y su compromiso en la lucha por la identidad, la recuperación y dignificación de la memoria del pueblo afrodescendiente, a través de su producción intelectual, como investigadores, narradores, folcloristas y poetas.

En este ensayo exaltamos al insigne poeta Jorge Artel. Poeta de su raza $\mathrm{y}$ de su gente, de sus tambores y de protestas llenas de vida, de negritud, de emoción sin límites, de angustia ancestral y llamado de la sangre.

Es el hombre cuya identidad se oye a gritos:

"Negro soy desde hace muchos siglos Poeta de mi raza heredé su dolor..."

(Negro soy)

Jorge Artel sobresalió como uno de los más insignes poetas de Colombia y del mundo hispano; poeta de su raza y de su ciudad.nació en Cartagena, bella ciudad, que en la Colonia configuró la piel negra como dispositivo legal para demarcar el tiempo y el territorio del mal, su sola mención bastaba para generar una avalancha de significaciones. El color negro fue el elemento que semantizó el territorio de los esclavizados para impedir que el mal se expandiera y territorializara demarcando el territorio del conflicto (Eljach, 2006). Este elemento ha estado presente desde entonces a lo largo de los siglos para mantener la demarcación moralizante impuesta por el poder colonial.

Heredero del compromiso poético de Candelario Obeso, luchador por la defensa de los valores culturales de su pueblo, de los bogas del río Magdalena, a través de su poesía y del testimonio del persistente retorno de un boga ausente de los cánones establecidos por la cultura oficial, pero inserto profundamente en las construcciones culturales de las comunidades afrocolombianas, Jorge Artel enriqueció su trabajo con los aportes de la afroantillanidad; Artel aborda en verso libre la tradición africana sin esencialismos ni exotismos propios de la mirada eurocéntrica, abiertamente colonial:

\section{“...La angustia humana que exalto}

No es decorativa joya

Para turistas.

iYo no canto un dolor de exportación!

(Negro soy)

Su poesía nos regala el mar, la naturaleza, la cotidianidad del ser caribe, el puerto, el viaje, la identidad, la rebeldía que duele de tanto doler; los ancestros, la negritud, las raíces, la memoria, la identidad, que se expresa en el tambor, en la gaita, en el cuerpo, en la unión con el entorno, como manifiesta en "La voz de los ancestros":

"Oigo galopar los vientos Bajo la sombra musical del puerto. 
Los vientos, mil caminos ebrios y sedientos,

Repujados de gritos ancestrales,

Se lanzan al mar.

Voces en ellos hablan

De una antigua tortura,

Voces claras para el alma

Turbia de sed y ebriedad

¿Oigo galopar los vientos,

Temblores de cadena y rebelión,

Mientras yo-Jorge Artel-

Galeote de un ansia suprema

Hundo remos de angustia en la noche!

Acercarse a Jorge Artel desde una mirada decolonial, es buscar esas voces otras que se rebelan, insumisas, incansables en su inacabada resistencia; es plantar un poema y una bota y una bandera, para hacer sentir la fuerza de quien se niega al silenciamiento de las narrativas hegemónicas:

"Poemas

Escritos con lágrimas

De un niño sin pan;

Con las manos podridas de un soldado

Que no volvió de la guerra;

Con el rencor de un negro

Linchado por las turbas del Sur;

Con las palabras de un obrero

Y la angustia de una patria encadenada,

Cumplid vuestro destino entre los hombres;

Prendidos de sus labios,

En el pulso de sus corazones, Marcando el ritmo igual y firme de sus pasos,

Hacia la libertad.
Hay un rumor de botas en el viento.

Brigadas de obreros, estudiantes y campesinos

Recogerán sus ecos

Sobre el curso indetenible que nos lleva

A un mundo ileso,

Sin explotadores,

Oligarquías y miseria.

$Y$ es esta la consigna:

imarchad, poemas!

(De Poemas, botas y banderas)

Jorge Turner en el Prólogo a Poemas con botas y banderas (1972), exalta lo siguiente: “...Artel escucha "la voz de sus ancestros" no solo porque lleve la sangre de los abuelos que en los galeones supieron del maltrato físico, la castración, el ronzal y el rebenque, sino porque su conciencia emocionada, de clase y de raza, y su temperamento artístico, le imponen el deber de escucharlos atenta y detenidamente; de manera distinta que con el oído pegado a la tierra; con el oído vuelto hacia adentro de sí mismo y un deseo inmenso de percibir, escucha el murmullo lastimero de sus antecesores, que cuando se vuelca en su poesía cobra el volumen del grito...” (pg. 13).

En ese comentario queda plasmada la naturaleza rebelde de la poesía de Jorge Artel, su compromiso con el pasado pero fundamentalmente con el presente: “...-lo que demuestra la proyección política inevitable que tiene el arte- un planteamiento decisivo para el cambio radical que en materia ideológica exige Colombia...": 
“... Era un turbión de ira.

El pueblo huracanado empujaba las horas con el pecho.

Pero nadie sabía la Consigna. -iMataron a Jorge EliécerA Jorge Eliécer Gaitán

Lo mataron por la espalda! Los fusiles caían en nuestras manos, Pero los caudillos no asistieron a la cita

Y el ímpetu nació desorientado...."

(Poemas con botas y banderas)

$\mathrm{Y}$ al evocar ese aciago 9 de abril de 1948, Jorge Artel demarca la línea de tiempo que han significado más de 70 años de violencia política ininterrupida; matizada, maquillada, enquistada en la entraña de la Colombia profunda que no cesa de llorar a sus muertos; y de lamentar la cobardía de los caudillos que no asistieron a esa cita...

Jorge Artel intuyó, supo, comprendió, que la modernidad es un pozo oscuro que con la retórica del progreso, oculta sus consecuencias, así como también oculta la energía irreductible de los marginados y excluidos de la tierra.

El pensamiento decolonial, contrapartida de la modernidad/colonialidad, se manifestó en Nuestramérica desde el pensamiento indígena y afrocaribeño, del que Jorge Artel es exponente egregio.

La genealogía del pensamiento decolonial, se remonta al mismo período de la Colonia en las voces insumisas e insurrectas que expresaron la inacabada resistencia, en manifestaciones como la de Waman Poma de Ayala en 1616 y de Ottabah Cugoano en 1787, con sus obras que fueron tratados políticos decoloniales, que la colonialidad del saber invisibilizó largo tiempo.

Estas manifestaciones de resistencia, abrieron las puertas a las voces y al pensamiento; otros, a la memoria y la historia de los pueblos originarios y de los africanos esclavizados en nuestro territorio; cuya memoria alienta en las lenguas y las experiencias de la esclavización de africanos mucho antes de que el pensamiento ilustrado eurocéntrico llegara a nuestro territorio; aun así Europa condenó la esclavitud, pero siguió narrando al indígena y al africano esclavizado como seres inferiores, salvajes, bárbaros, sin alma; sujetos exóticos para su asombro y diversión. Frente a esto se rebeló Jorge Artel, y dictó su propio credo:

Creo en la estrella

Que contra el mundo enceguecido

$\mathrm{Su}$ ineludible luz desata;

En la libertad de los espíritus,

En la paz entre los pueblos

Y la igualdad de las razas....

Creo en los niños hambrientos

Cuyos padres son pasto de cañón

Y nervio de las fábricas,

Esclavos de la avidez capitalista

En una sociedad parasitaria.

Creo en la juventud sin cadenas,

Reinvindicada de prejuicios,

Limpia de cuerpo y de alma;

En su pensamiento estremecido

$Y$ en el poder de la palabra....

Creo en el poder de los humildes,

Los desterrados y los perseguidos 
A quienes se niega el sol, la sal, el agua;

Creo en el triunfo postrer de los de abajo

Porque de ellos es el día de mañana..."

(Credo)

Es aceptar el reto de asumir la resistencia que hoy se expresa en los condenados de la tierra, los danmés de la terre, en clave de Frantz Fanon (1961) de los que hace reflexión Nelson Maldonado Torres (citado por Mignolo, 2007), migrantes, pobres, informales, las multitudes pasto de la aporofobia.

Es reclamar las voces planetarias de Ottobah Cugoano, Egnatius Sancho, John Marrant y Loudah Equiano; Patrice Lumumba, Marcus Garvey, Aimé Césaire, Nelson Mandela, Leopoldo Sédar Senghor y León G. Damas; del gran poeta Langston Hughes, de Frantz Fanon, Michel Trouillot y de extraordinarios pensadores afrocaribeños y afrocolombianos como Candelario Obeso, Manuel Zapata Olivella, Arnoldo Palacios, Miguel A. Caicedo, Sofonías Yacup, Alfredo Vanín, Helcías Martán Góngora, Mary Grueso, María Teresa Ramírez, entre muchos otros; con el poeta repetimos:

"Hay un rumor de botas en el viento. Brigadas de obreros, estudiantes y campesinos

Recogerán sus ecos

Sobre el curso indetenible que nos lleva

A un mundo ileso,

Sin explotadores,

Oligarquías y miseria.
$Y$ es esta la consigna:

imarchad, poemas!"

(De Poemas, botas y banderas)

Nuestramérica siempre tuvo su propia voz, opuesta, en resistencia al pensamiento único, universalizante, que forzó la invisibilización con una historia de quinientos y un poco más de invasión a los otros del mundo. Este pensamiento decolonial es históricamente construido no por personalidades, sino por los movimientos sociales que hoy siguen escribiendo la historia.

Es querer oír a Artel diciendo a toda voz que no necesitamos las retóricas salvacionistas de los que proclaman la modernidad que nos "descubre" para invisibilizarnos, para condenarnos al silenciamiento de las muchas voces que nos definen en el canto, en la oración, en el grito, en el abrazo.

Es reclamar nuestra acción en el ahora y en estos tiempos que exigen nuestra presencia:

"Te amamos, paz, En la presunta llama

Que sólo enciende el beso;

En la mañana pura

Que aflora tras los ojos de los niños;

En ese silencio azul

Donde las olas lavan sus estrellas.

Te amamos, paz,

Y tú no llegas."

(Poemas con botas y banderas)

En la energía telúrica que caracteriza a nuestros pueblos que no aceptan nunca más ser manipulados, ex- 
plicados, entendidos, traducidos, por la racionalidad del colonizador.

Y sí en las muchas enseñanzas y experiencias de la esclavización y de la diáspora africana en nuestros territorios. Es recuperar el saber situado e históricamente construido:

"Negros de nuestro mundo, Los que no enajenaron la consigna,

Ni han trastocado la bandera, Este es el evangelio:

Somos -sin odios ni temoresUna conciencia en América..."

(Poema sin odios ni temores)

\section{Conclusión}

En la poesía de Jorge Artel se encuentran todos los elementos que configuran un discurso desde el enfoque decolonial, la resistencia al lenguaje modernizador, un carácter reinvindicatorio y una necesidad emancipadora.

Jorge Artel intuyó, supo, comprendió, que la modernidad es un pozo oscuro que con la retórica del progreso, oculta sus consecuencias, así como también oculta la energía irreductible de los marginados y excluidos de la tierra.

La palabra poética de Jorge Artel es una ruta, evocación y canto; también historia y reclamación y grito. Es la voz de los ancestros que se alza desafiante para advertirnos que a pesar de los siglos trasegados, de los vientos aciagos, de las muchas violencias que siguen asolando campos y ciudades de la patria, de los muchos caídos y olvidados, de los caudillos cobardes que abandonaron el barco y dejaron a la deriva a un pueblo ávido de liderazgos, la poesía de la gente negra, de aquellos que como Jorge Artel y Candelario Obeso, siguen repicando la inacabada resistencia de los pueblos del mundo, en el clamor planetario por la vida, que es lo mismo que defender el aire, el agua, los derechos de los niños y las mujeres y hombres y los ancianos y la lucha de los pueblos indígenas, y de los jóvenes y de los artistas y de los poetas de mundo, por el sagrado derecho a vivir en paz:

Te amamos, paz,

Y tú no llegas

$Y$ es esta la consigna:

imarchad, poemas!

(De Poemas, botas y banderas) 


\section{Referencias}

Archila, M. (2010). Idas y venidas, vueltas y revueltas: protestas sociales en Colombia, 1958-1990. Bogotá: Colombia. CINEP.

Artel, J. (1972). Poemas con botas y banderas. Barranquilla, Colombia: Ediciones Universidad del Atlántico.

Artel, J. (1972). Tambores en la noche. Colombia: Ministerio de Cultura.

Artel Alcázar, J. N. (2004). Tambores en la noche y selección de poesía inédita. Barranquilla, Colombia: Nobel Impresores Ltda.

Cabarcas O. M. J. (2013). La figuración poética de la identidad: lo negro en Tambores en la Noche de Jorge Artel. Estudios de literatura colombiana, 32, 73-86. Universidad del Atlántico, Barranquilla.

De Certau, M. (1986). The practice of every day life. Berkeley, Estados Unidos: California UP.

De Sousa Santos, B. (2009). Epistemologías del Sur. México: Siglo XXI.

Díaz A. J, (2009). La construcción de lo afro en la poética de Jorge Artel, Revista Cuadernos de literatura del Caribe e Hispanoamérica, 9, 95-106.

Duncan, Q. (2013). El afrorrealismo en Nicolás Guillén y Jorge Artel. Revista Comunicación, 22,(1). Instituto Tecnológico de Costa Rica.

Eljach, M. (2006). La construcción jurídica del negro en la Colonia. Popayán, Colombia: AXIS MUNDI Editores.

Fanon, F. (1961). Los condenados de la tierra. París, Francia: Editorial Grove Press.

Lawo-Sukam, A. (2010). Hacia una poética afro-colombiana: el caso del Pacífico. Universidad del Valle. (Presentación).

Mignolo, W. (2007). El pensamiento decolonial: desprendimiento y apertura: un manifiesto. En: El giro decolonial. Reflexiones para una diversidad epistémica más allá del capitalismo global (pp. 25-46). Bogotá, Colombia: Editores Santiago Castro-Gómez, Ramón Grosfoguel.

Obeso, C. (2009). Cantos populares de mi tierra Bogotá, Colombia: Ministerio de Cultura, Alcaldía Mayor de Bogotá.

Ortega H., M. (2006). Temáticas recurrentes en la poesía de Jorge Artel, Cuadernos de Literatura del Caribe e Hispanoamérica. Barranquilla, Colombia: Universidad del Atlántico,

Rodríguez, H. N. (2014). La poética de Jorge Artel, más allá del Estado nación. Revista semestral de la Cátedra de la Lengua y Literatura hispanoamericana, 24(1), 39-63. Universidad Católica del Sacro Cuore, Milano, Italia. Centroamericana. 